\title{
Health Referral System for Non-Specialized Cases in Southeast Sulawesi Province, Indonesia
}

\author{
Sistem Rujukan Kesehatan pada Kasus Non Spesialistik \\ di Provinsi Sulawesi Tenggara, Indonesia
}

\author{
Sartini Risky*1 Faridah M. Said ${ }^{2}$, Asbath Said ${ }^{3}$, Lodes Hadju ${ }^{4}$ \\ ${ }^{1,4}$ Bagian Kesehatan Masyarakat, Universitas Mandala Waluya, Kendari \\ ${ }^{2}$ Bagian Keperawatan, Lincoln University Collage, Kuala Lumpur \\ ${ }^{3}$ Bagian Keperawatan, Universitas Mandala Waluya, Kendari
}

DOI: $10.24252 /$ al-sihah.v13i2.25951

Received: 25 December 2021 / In Reviewed: 25 December 2021 / Accepted: 29 December 2021 / Available online: 31 December 2021 (C) The Authors 2021. This is an open access article under the CC BY-NC-SA 4.0 license

\begin{abstract}
The government prioritizes health as one of the areas in which it seeks to boost the country's growth, but the referral system in place has failed to deliver high-quality health care. The purpose of this study was to assess and empirically demonstrate the extent to which the health referral system has been implemented in Kendari Health Center and Bau-Bau City. The study was placed in the Kendari City Health Center and the Bau-Bau City Health Center, and it lasted from February 2020 to February 2021. This research method is a qualitative approach based on postpositivism's theory, in which the researcher is the primary instrument, triangulation is used to collect data, inductive data analysis is used to analyze data, and qualitative research results emphasize meaning rather than generalization. Informants in this study amounted to 15 informants. Qualitative data were analyzed using the NVIVO 12 QSR application. The research findings indicate that there is a conceptual link between the health system and the concept of implementing a referral system. This research emphasizes to the health service center the importance of increasing the knowledge of health workers through training for both doctors and advocacy for policymakers regarding the improvement of health facilities.
\end{abstract}

\begin{abstract}
ABSTRAK
Kesehatan merupakan salah satu hal yang menjadi perhatian pemerintah dalam rangka meningkatkan pembangunan negara, namun sistem rujukan yang diselenggarakan belum memberikan pelayanan kesehatan secara bermutu. Tujuan yang ingin dicapai melalui penelitian ini adalah untuk menganalisis dan membuktikan secara empiris sejauh mana pelaksanaan sistem rujukan kesehatan di Puskesmas Kota Kendari dan Kota Bau-Bau. Penelitian ini dilaksanakan di Puskesmas Kota Kendari dan Puskesmas Kota Bau-Bau dan waktu penelitian yaitu pada bulan Februari 2020 sampai selesai. Metode penelitian ini adalah metode kualitatif yang berlandaskan pada filsafat postpositivisme, dimana peneliti adalah sebagai instrument kunci, teknik pengumpulan data dengan triangulasi, analisis data bersifat induktif, dan hasil penelitian kualitatif lebih menekankan makna dari pada generalisasi. Informan pada penelitian ini berjumlah 15 informan. Data kualitatif dianalisis menggunakan aplikasi QSR NVIVO 12. Temuan penelitian menunjukkan terdapat keterkaitan konsep antara sistem kesehatan dengan konsep pelaksanaan sistem rujukan. Penelitian ini menekankan kepada pihak puskesmas peningtingnya peningkatan pengetahuan tenaga kesehatan melalui pelatihan-pelatihan baik itu untuk dokter serta melakukan advokasi kepada pembuat kebijakan terkait peningkatan fasilitas kesehatan.
\end{abstract}

\section{GRAPHICAL ABSTRACT}

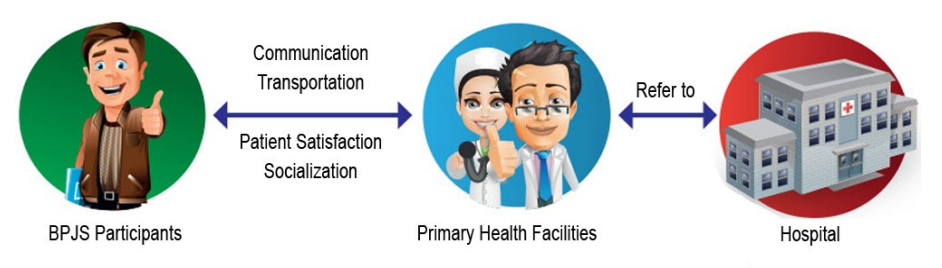

Keyword

health insurance; healthcare referral system; health system; patient communication; patient satisfaction

Kata Kunci:

asuransi kesehatan; kepuasan pasien; komunikasi pasien; sistem kesehatan; sistem rujukan puskesmas

* Correspondence

Jln. Gersamata No. 32 Wua-Wua, Kendari Sulawesi Tenggara 93117

Email: risky.sarjan87gmail.com 


\section{PENDAHULUAN}

Fasilitas Kesehatan Tingkat Pertama (FKTP) sebagai gatekeeper di era JKN wajib memberikan pelayanan primer yang komprehensif dengan pelayanan kesehatan yang berkualitas (Sari et al., 2020).. Di era $\mathrm{JKN}$, pelayanan kesehatan menggunakan sistem rujukan berjenjang dengan pembagian tugas dan fungsi dari setiap penyedia pelayanan kesehatan (Alawi et al., 2015). Puskesmas memiliki peranan penting dalam penyelenggaraan Sistem Jaminan Kesehatan Nasional (Yusuf \& Awwaliyah, 2020). Diberlakukannya program JKN membuat masyarakat yang akan berobat kerumah sakit dengan kartu BPJS harus mendapat rujukan terlebih dahulu dari Puskesmas (Zulhadi et al., 2013).

Kota Kendari dan Kota Bau-Bau merupakan 2 kota di Sulawesi Tenggara yang terdiri dari 15 Puskesmas untuk Kota Kendari dan sekitar 17 Puskesmas untuk Kota Bau-Bau. Dari angka rujukan di Sulawesi Tenggara 2 daerah ini memiliki angka rujukan di Puskesmas Perawatan untuk kasus non spesialistik yang cukup tinggi dibandingkan dengan kabupaten yang lain yaitu 278 rujukan untuk Kota Bau-Bau dan 130 rujukan untuk Kota Kendari. Angka rujukan di Puskesmas perawatan untuk kasus non spesialistik pada Kota Kendari mengalami peningkatan kasus yaitu untuk tahun 2016 sebanyak 9 kasus kemudian meningkat di tahun 2017 sebanyak 25 kasus, dan ditahun 2018 tetap mengalami peningkatan yaitu 130 kasus rujukan non spesialistik. Sedangkan untuk di Kota BauBau untuk tahun 2016 yaitu sebesar 146 kasus kemudian meningkat di tahun 2017 menjadi 417 kasus dan ditahun 2018 yaitu sebesar 278 kasus. (BPJS Kesehatan Cabang Kendari, 2019; BPJS Kesehatan Cabang Bau-Bau, 2019; Anhar et al., 2016)

Permasalahan rujukan di Sulawesi Tenggara masih cukup kompleks. Berdasarkan studi awal pendahuluan yang dilakukan oleh peneliti di beberapa Puskesmas ditemukan ada beberapa permasalahan terkait sumber daya manusia, waktu, pelayanan dan biaya, sarana prasarana. Penerapan sistem tidak akan berjalan dengan baik jika implementasi tidak sesuai dengan ketentuan kebijakan atau pedoman. Salah satu masalah dari implementasi sistem rujukan adalah kurangnya sumber daya dan infrastruktur yang penting dari pelayanan medis dalam menyediakan layanan kesehatan yang standar. Kekurangan sumber daya yang dimiliki Puskesmas dan masalah lain yang dihadapi oleh Puskesmas, diperlukan integrasi dengan bidang yang berbeda untuk mendukung dan memaksimalkan pelayanan puskesmas (Chabibah, 2012).

Beberapa penelitian mengemukakan berbagai keluhan yang dialami peserta BPJS di beberapa puskesmas (Novitasari et al., 2018; Lail, 2019; Ratnasari, 2017). Hasil observasi Puskesmas wilayah peneliti ditemukan beberapa keluhan lain terkait sistem rujukan BPJS yang dirasakan adalah kurangnya fasilitas di layanan kesehatan primer dan beberapa fasilitas yang rusak sehingga penyakit yang dapat ditangani di tingkat pelayanan primer sekunder akan tetapi langsung dirujuk ke rumah sakit tingkat tersier. Keluhan lain yang diungkapkan oleh para PNS yaitu jika proses rujukan melewati layanan puskesmas, mereka mera- 
sa proses tersebut menghabiskan waktu dan jam kerja mereka. Yang dimana harapannya para PNS tidak mengalami kesulitan dan seharusnya sistem rujukan dapat diperoleh dari layanan primer lain seperti klinik bukan saja hanya dari Puskesmas. Kondisi dilapangan yang terjadi ada beberapa pasien yang meminta rujukan sendiri, bahkan beberapa diantara mereka bersikeras meminta rujukan padahal kondisi kesehatan pasien tidak seharusnya dirujuk. Hal ini menjadi bahan perdebatan antara dokter dan petugas kesehatan dengan pasien .

Amini (2017) dalam penelitian mengkaji pelaksanaan sistem rujukan dari perspektif pengiriman layanan (komunikasi,koordinasi dan kerjasama), aspek tenaga kesehatan. Dari hasil penelitiannya ditemukan bahwa keenam komponen di atas memberikan kontribusi terhadap pelaksanaan sistem rujukan. Kemudian lebih lanjut penelitian yang dilakukan oleh Naseriasl (2018) yaitu reformasi sistem perawatan, reformasi sistem pendidikan, pembayaran reformasi sistem, dan meningkatkan pembangunan budaya dan pendidikan publik secara efektif mempengaruhi implementasi dan peningkatan sistem rujukan di Indonesia Iran.

Penelitian yang akan dilakukan, meskipun fokusnya sama dengan penelitian di yang telah dilakukan yaitu analisis pelaksanaan sistem rujukan, namun dalam penelitian ini kajian lebih ditekankan dan berfokus terhadap komponen sistem rujukan yang dikemukakan oleh WHO. Dalam menganalisis pelaksanaan sistem rujukan kesehatan, tulisan ini juga mencoba menggabungkan beberapa jurnal internasional yang terkait dengan sistem rujukan sistem kesehatan. Pengolahan data, reduksi dan display dan analisis data dalam penelitian ini juga menggunakan perangkat lunak (software) NVIVO 12 yang belum dilakukan pada penelitian sebelumnya terkait topik penelitian ini. Berdasarkan uraian diatas, maka perlu suatu upaya dalam penataan sistem rujukan yang efektif dan terstruktur, sehingga perlu dilakukan suatu penelitian untuk menganalisis pelaksanaan sistem rujukan kesehatan kasus non spesialistik di Puskesmas Kota Kendari dan Kota Bau-Bau.

\section{METODE PENELITIAN}

Penelitian ini termasuk dalam kelompok penelitian kesehatan. Yang memfokuskan kegiatan pada masalah-masalah yang timbul di bidang kesehatan/ kedokteran dan sistem kesehatan. Penelitian ini berfokus pada analisis pelaksanaan sistem rujukan kesehatan di Puskesmas di Kota Kendari dan Kota BauBau. Komponen analisis pelaksanaan sistem rujukan difokuskan pada sistem kesehatan berupa jasa penyedia dan kualitas pelayanan

Desain penelitian ini adalah kualitatif berdasarkan filosofi postpositivisme digunakan untuk meneliti keadaan objek alam di mana peneliti adalah alat yang penting pengambilan sampel sumber data terarah dan bola salju, teknik pengumpulan data adalah triangulasi analisis data Temuan penelitian kualitatif dan induktif menekankan signifikansi daripada generalisasi. 
Penelitian ini dilaksanakan di Puskesmas Kota Kendari dan Puskesmas Kota Bau-Bau dan waktu penelitian yaitu pada bulan Februari 2020-Februari 2021. Sumber data dan informasi penelitian berasal dari informan yang berhubungan dengan pelaksanaan sistem rujukan kesehatan di Puskesmas. Adapun yang menjadi informan dalam penelitian ini yaitu: 1) Kantor BPJS Kesehatan cabang Kendari yang terdiri dari Kepala Puskesmas Rawat Inap Kota kendari, Dokter Puskesmas rawat inap Kota Kendari, staf Pcare, Kepala Bidang Penjaminan Manfaat Primer (PMP) Di wilayah kerja cabang Kendari, penanggung jawab rekam medis RS dan 4 pasien rujukan di Puskesmas rawat inap, dan 2) Kantor BPJS Kesehatan cabang Bau-Bau yang terdiri dari Kepala Puskesmas Rawat Inap Kota BauBau, Dokter Puskesmas rawat inap Kota Bau-Bau, staf Pcare, Kepala Bidang Penjaminan Manfaat Primer (PMP) Di wilayah kerja cabang Bau-Bau dan 4 pasien rujukan di Puskesmas rawat inap.

Dalam penelitian kualitatif instrumen utamanya adalah peneliti sendiri, namun selanjutnya setelah fokus penelitian menjadi jelas, maka kemungkinan akan dikembangkan instrumen penelitian sederhana,yang diharapkan dapat melengkapi data dan membandingkan dengan data yang telah ditemukan melalui observasi dan wawancara. Peneliti akan terjun ke lapangan sendiri, baik pada tahap wawancara,tahap fokus dan seleksi, melakukan pengumpulan data, analisis dan membuat kesimpulan. Dalam penelitian ini, peneliti akan menggunakan beberapa jenis teknik pengumpulan data, yaitu Observasi, wa- wancara, dan dokumentasi.

Analisis data yang digunakan penulis adalah analisis data hasil wawancara menggunakan aplikasi QSR NVIVO 12. Validasi data dilakukan dengan mentriangulasi sumber-sumber data yang berbeda dengan memeriksa bukti-bukti yang berasal dari sumber-sumber tersebut dan menggunakannya untuk membangun justifikasi tema-tema secara koheren. Serta menerapkan member checking untuk untuk mengecek apakah responden merasa bahwa laporan/deskripsi/tema tersebut sudah akurat.

\section{HASIL PENELITIAN}

Penelitian ini melibatkan analisis implementasi sistem rujukan medis di Puskesmas di Kota Kendari dan Kota Bau-Bau. Penelitian ini berdasarkan dengan teori lanjutan World Health Organization (2008) tentang komponen sistem rujukan kesehatan.

Aspek pertama dalam sistem kesehatan adalah jasa penyedia dan kualitas layanan, di Puskesmas, hal ini berkaitan dengan pola komunikasi penyedia layanan baik dengan pemegang kebijakan maupun dengan pengguna layanan, ketersediaan sarana transportasi dalam layanan rujukan Puskesmas, kepuasan pasien dan sosialisasi jika terdapat kebijakan baru dalam sistem rujukan kesehatan.

Berkaitan dengan penyelenggaraan sistem rujukan kesehatan, pola komunikasi di tingkat penyelenggara layanan kesehatan, dalam hal ini Puskesmas terbangun sangat baik. Hal ini sesuai dengan wawancara dengan informan staf Pcare Puskesmas 
Lepo-lepo Kota Kendari sebagai berikut:

"Kalo saya dengan dokter di poli, harus ada koordinasi karena kadang ada namanya yang bisa dirujuk ada yang tidak bisa di rujuk, jadi saya harus koordinasi dengan dokter, misalnya kalo baru pertama kan ada pasien yang minta rujukan kalo dokter yang sudah, maksudnya dokter yang sudah lama disini kan sudah tau toh ini yang bisa dirujuk, kalo dokter internship kan kadang mereka nda tau, pasien minta di kasih saja jadi itu saya harus kasih tau.saya bilang dok itu nda boleh di kasih kita obati dulu nanti kedua kali kalo pasiennya tidak sembuh sembuh baru pasiennya kita rujuk." staf Pcare Puskesmas Lepo-Lepo, AT (45 Tahun)

Hal tersebut diperkuat dengan pernyataan dari Kepala Puskesmas Bukit Wolio Indah Kota Bau-bau sebagai berikut:

"Kita selalu komunikasi, Kalau untuk di puskesmas itu ada laporan yang bertanggung jawab petugas Pcare, dia lapornya harian update. Nanti fungsinya kami kepala puskesmas, mengawasi apakah sudah melapor, masuk laporannya atau belum." Kepala Puskesmas BWI, HN (39 Tahun)

Terkait dengan komunikasi dengan pemegang kebijakan dalam hal ini Dinas Kesehatan dan BPJS juga terbangun dengan baik hal ini sesuai dengan pernyataan dari staf Pcare Puskesmas Bungi, yaitu:

Selama ini saya paling sering komunikasi dengan dokter dan pihak BPJS karena laporannya kami langsung ke BPJS karena kan sistemnya online. Kalau jika biasa kami diskusi kalau ada pasien-pasien yang minta rujukan sendiri disitu dokter men- jelaskan dulu.(Wawancara dengan staf Pcare Puskesmas Bungi, MR (30 Tahun), tanggal 21 Agustus 2020)

Pendapat ini diperkuat dengan penjelasan dari Dinas Kesehatan Kota BauBau, yaitu:

"Iya,,kami komunikasi dengan puskesmas dan BPJS." Kasi Pelayanan Dinkes Kota Bau-bau, YN (47 Tahun)

Hal ini lebih dipertegas dengan pernyataan dari hasil wawancara dengan BPJS Kendari sebagai berikut:

"Kami selalu komunikasi di puskesmas dan dinas, Kalau di FKTP itu, ada grup telegram, ada grup WA. Kalau grup telegram itu antara FKTP dan FKTL, kalau ada mau merujuk itu, kalau ada kendala rujukan diselesaikan disitu. Kami sebagai BPJS ada juga dalam setiap, kami juga melihat, kalau grup WA khusus FKTP. Jadi kalau ada kendalanya, langsung ji mereka bicara di grup. Terus ada pertemuan juga, ada evaluasi kami. Biasa kita bikin triwulan atau per-semester. Ini barubaru kita bikin." Kabid Penjaminan Manfaat BPJS Kota Kendari, NW (37 Tahun)

Berkaitan dengan komunikasi dengan pengguna layanan dalam hal ini pasien di Puskesmas, juga telah terbangun dengan baik, hal ini berdasarkan penelusuran dengan metode wawancara FGD dengan pasien di Puskesmas Abeli sebagai berikut:

"Untuk petugas ramah, biasa kita bertanya langsung dijawab, jadi kami senang datang ke puskesmas." Pasien Puskesmas Abeli, WF (54 Tahun)

Namun beberapa pasien juga 
mengeluhkan kurang ramahnya beberapa petugas kesehatan di Puskesmas, sehingga tidak dapat terjalin komunikasi yang baik dalam penyelenggaraan sistem rujukan di Puskesmas. Hal ini berdasarkan wawancara dengan pasien di Puskesmas Abeli Kota Kendari, sebagai berikut:

"Ada beberapa petugas yang kurang bersahabat kalau kita bertanya." Pasien Puskesmas Abeli, AA (38 Tahun)

Berdasarkan hasil wawancara dengan berbagai sumber maka dapat dikemukakan bahwa komunikasi cukup baik dibangun oleh para penyelenggara, dalam hal ini Dokter, Kepala Puskesmas, Dinas Kesehatan dan BPJS. Namun diperlukan perhatian yang lebih guna terjalinnya komunikasi yang baik dengan pasien, sehingga dengan begitu kebijakan dan aturan mengenai sistem rujukan kesehatan dapat tersosialisasi dengan baik sampai ke level terbawah, dalam hal ini pasien sebagai pengguna jasa layanan.

Guna menunjang penyelenggaraan sistem rujukan kesehatan yang efektif, Puskesmas harus didukung dengan sarana transportasi untuk pengantaran pasien gawat darurat ke tempat rujukan. Dalam hal ini seluruh Puskesmas yang masuk dalam sampel telah memiliki kendaraan ambulance sendiri untuk mobilisasi pasien ke tempat rujukan. Informasi ini diperoleh dari hasil wawancara dengan Kepala Puskesmas Lepo -Lepo sebagai berikut:

"Ada ambulans di puskesmas, 24 jam kami stand by kan itu. Permintaan transportasi tergantung mi pasien, kadang kadang memang sama sekali saran untuk itu kami tetap pake ambu- lans, dan siap kami operasikan kapanpun." Kepala Puskesmas Lepolepo, HM (41 Tahun)

Yang diperkuat dengan pernyataan pasien Puskesmas Abeli, sebagai berikut:

"Iya standby terus mobilnya." Puskesmas Abeli, ND (43 Tahun)

Keberadaan alat transportasi di Puskesmas juga terkadang tidak dimanfaatkan oleh beberapa pasien rujukan, hal ini berdasarkan pernyataan staf Pcare Puskesmas Abeli sebagai berikut:

"Untuk sistem transportasi di Puskesmas kami selalu standby ambulance,tapi ada beberapa pasien yang membawa kendaraan sendiri." Staf Pcare Puskesmas Abeli, SM (42 Tahun)

Yang diperkuat dengan pernyataan dari pasien Puskesmas Abeli berikut:

"Ada terus mobil di puskesmas tapi saya biasa ada kendaraan sendiri”. Pasien Puskesmas Abeli, AD (45 Tahun)

Berdasarkan informasi-informasi tersebut dan hasil observasi di lapangan, dapat dikemukakan bahwa di setiap Puskesmas sudah tersedia kendaraan operasional Puskesmas dalam hal ini mobil Ambulance yang siap setiap saat untuk dimanfaatkan oleh pasien rujukan Puskesmas ke tempat rujukan walaupun terkadang tidak dimanfaatkan oleh pasien yang sudah memiliki kendaraan pribadi.

Kualitas pelayanan sistem rujukan berakhir pada kepuasan pasien sebagai penerima manfaat, berdasarkan wawancara dengan petugas kesehatan, dalam hal ini dokter, mereka merasa bahwa pasien cukup puas dengan kualitas pelayanan saat ini, hal 
ini diperoleh berdasarkan wawancara dengan dokter Puskesmas Lepo-lepo Kota Kendari sebagai berikut:

"Sejauh ini mereka cukup puas dengan pelaksanaan sistem rujukan di puskesmas." dokter Puskesmas Lepo-lepo, DW (58 Tahun)

Yang juga diperkuat dengan pernyataan dokter Puskesmas Bukit Wolio Indah Kota Bau-bau, yaitu:

"Iya, karena untuk sekarang hanya beberapa persen pasien yang meminta rujukan sendiri." dokter Puskesmas BWI, EM (39 Tahun)

Berdasarkan hasil wawancara mendalam dengan beberapa informan, diperoleh informasi bahwa beberapa pasien tidak merasa puas dengan pelaksanaan sistem rujukan Puskesmas yang tidak memperkenankan pasien untuk memilih FKTL sendiri, hal ini diperoleh dari hasil wawancara dengan informan dokter Puskesmas Bungi Kota Bau-Bau berikut:

"Ada beberapa yang kurang puas,seperti terkadang ada pasien yang meminta rujukan sendiri". dokter Puskesmas Bungi, WD (29 Tahun)

Hal ini diperkuat oleh pernyataan informan pasien Puskesmas Abeli yang merasa puas, namun mengeluhkan alur rujukan sebagai berikut:

"Saya cukup puas dengan pelayanan rujukan disini hanya saya kalau kita minta rujukan maunya janganmi ditolak." Pasien Puskesmas Abeli, ND (43 Tahun)

Yang ditambahkan oleh informan pasien Puskesmas Lepo-lepo, yakni:

"Saya masih kurang puas karena sekarang sudah tidak bisa kita memilih tempat rujukan sendiri dulu itu boleh dimana saja." Pasien Puskesmas Lepo-lepo, RD (60 Tahun)

Berdasarkan informasi-informasi tersebut di atas, dapat dikemukakan bahwa dalam hal pelayanan rujukan di Puskesmas sebagian besar pasien merasa cukup puas, ketidakpuasan hanya ada pada pasien yang tidak mau mengikuti aturan baru mengenai alur rujukan pasien yang telah ditetapkan BPJS dengan memilih tempat rujukan sendiri.

Dalam pelaksanaan sistem rujukan kesehatan di Puskesmas seringkali terjadi perubahan kebijakan oleh BPJS setiap waktu, sehingga diperlukan sosialisasi setiap kali adanya perubahan kebijakan terkait dengan sistem rujukan. Hal ini berdasarkan wawancara dengan informan dari BPJS Bau-bau sebagai berikut:

"Setiap ada regulasi-regulasi baru, kami di BPJS kesehatan memang wajib mensosialisasikan, jadi tidak akan dilaksanakan dulu kalau belum tersosialisasi, jadi begitu dia sistemnya di BPJS kesehatan." Kabid Penjaminan Manfaat BPJS Kota Baubau, AM (32 Tahun)

Sosialisasi kebijakan baru seringkali dilaksanakan oleh BPJS sebagai pembuat kebijakan, hal ini berdasarkan wawancara dengan informan Dinas Kesehatan Kota Bau-bau, yaitu:

"Iya,,tapi kebanyakan BPJS itu yang lebih sering sosialisasi." Kasi Pelayanan Dinkes Kota Bau-bau, YN (47 Tahun)

Yang diperkuat dengan pernyataan Informan BPJS Kendari sebagai berikut: 
"Iya,, kami selalu melakukan sosialisasi jika ada regulasi baru terkait sistem rujukan." Kabid Penjaminan Manfaat BPJS Kota Kendari, NW (37 Tahun)

Berdasarkan informasi-informasi diatas, dapat diperoleh kesimpulan bahwa dengan adanya kebijakan maupun aturan baru mengenai sistem rujukan kesehatan, BPJS wajib mensosialisasikan kepada penyelenggara layanan kesehatan berkoordinasi dengan Dinas Kesehatan selaku instansi yang membawahi seluruh Puskesmas di wilayahnya.

Pada Gambar 1 menyajikan hasil analisis menggunakan Nvivo yang menunjukkan keterkaitan antara konsep jasa penyedia dan kualitas layanan dengan konsep pelaksanaan sistem rujukan memiliki keterkaitan konsep. Ini bisa dilihat dari beberapa indikator jasa penyedia dan kualitas layanan yaitu terdapat 30 informasi yang menyatakan keterkaitan antara konsep kepuasan terhadap pelaksanaan sistem rujukan, terdapat 42 informasi yang menyatakan keterkaitan antara konsep komunikasi terhadap pelaksanaan sistem rujukan. terdapat 34 informasi yang menyatakan keterkaitan antara konsep sistem transportasi terhadap pelaksanaan sistem rujukan serta terdapat 21 informasi yang menyatakan keterkaitan antara konsep sosialisasi terhadap pelaksanaan sistem rujukan.

\section{PEMBAHASAN}

\section{Komunikasi}

Berdasarkan hasil penelitian bahwa secara umum komunikasi yang dibangun sudah cukup baik antara para penyelenggara yang terlibat dalam sistem rujukan kesehatan, dalam hal ini adalah staf Pcare di Puskesmas, dokter Puskesmas, Kepala Puskesmas, Dinas Kesehatan, hingga ke BPJS Kesehatan sebagai pengelola utama sistem rujukan kesehatan. Hal inilah yang menyebabkan sistem rujukan kesehatan sampai saat ini masih terselenggara dengan baik dari fasilitas kesehatan tingkat pertama dalam hal ini Puskesmas sebagai penyelenggara rujukan ke fasilitas kesehatan tingkat lanjut.

Komunikasi antar organisasi sangat mempengaruhi jasa pelayanan dan kualitas pelayanan dalam sistem rujukan kesehatan (Meesala \& Paul, 2018). Komunikasi yang dibangun saling terhubung satu sama lain. Berdasarkan penelusuran melalui proses wawancara dan observasi secara langsung, pola komunikasi terjalin dari tingkat terbawah, yaitu antara dokter dan petugas Pcare di tiap Puskesmas yang saling mengkomunikasikan sistem rujukan pasien setelah pemeriksaan. Komunikasi selanjutnya pada tingkat Puskesmas adalah antara petugas Pcare Puskesmas dengan Kepala Puskesmas yang dilakukan setiap saat berkaitan dengan angka rujukan. Komunikasi antara dokter Puskesmas dan Kepala Puskesmas juga terjadi, seringkali terkait dengan kendala yang dihadapi dalam sistem rujukan pasien, dalam hal ini berhubungan dengan kebutuhan sarana dan prasarana dalam upaya pengentasan 144 penyakit non spesialistik yang harus tuntas di tingkat Puskesmas.

Hasil temuan peneliti menekankan perbaikan pola komunikasi antara penyelenggara sistem rujukan kesehatan dengan masyarakat, secara terkhusus dalam hal ini 
Gambar 1

Hubungan Jasa Penyedia dan Kualitas Layanan dengan Pelaksanaan Sistem Rujukan Kesehatan

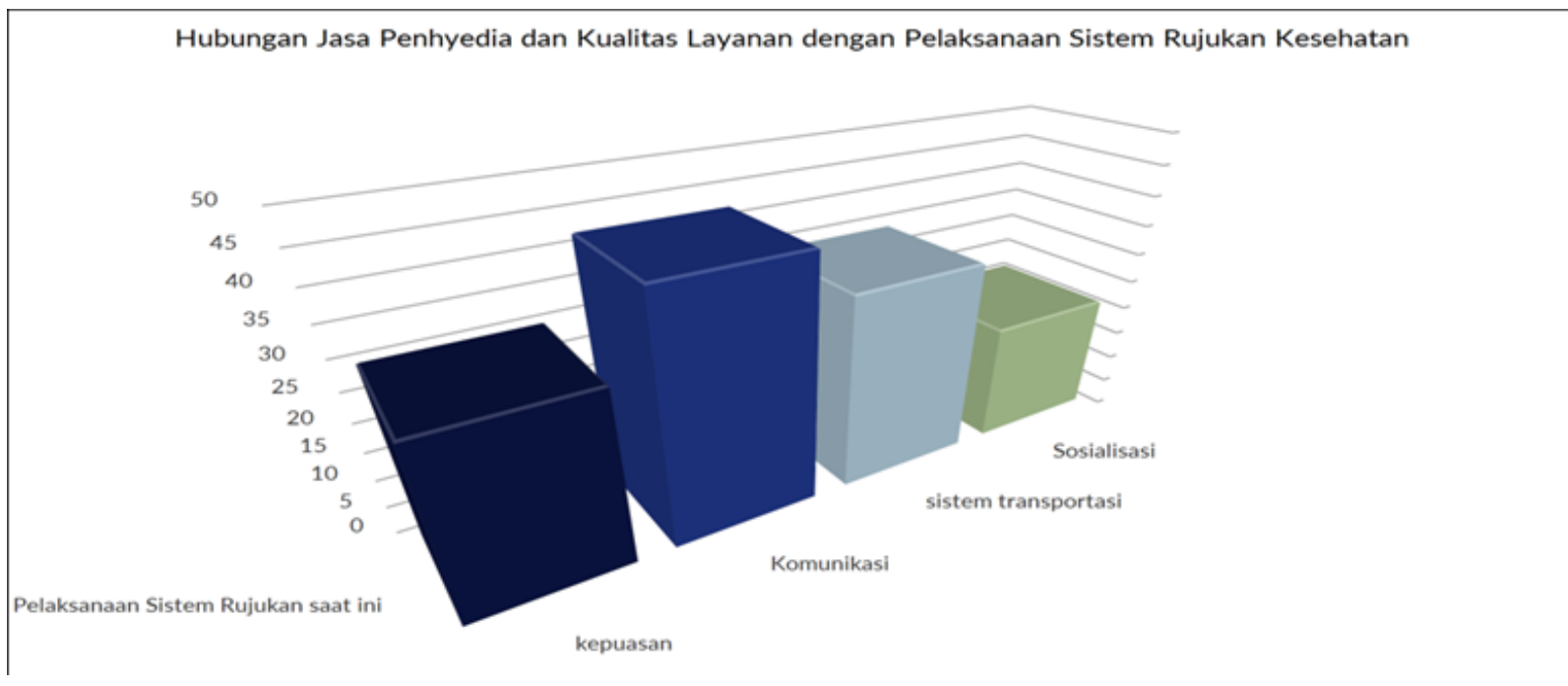

adalah pasien sebagai penerima manfaat pelayanan Puskesmas. Dari hasil focus group discussion dengan beberapa pasien, diperoleh kesimpulan bahwa beberapa pasien mengeluhkan adanya sebagian petugas kesehatan yang kurang ramah dalam berkomunikasi dengan pasien. Hal ini dapat memberikan pengaruh pada persepsi masyarakat dalam menilai kualitas layanan dan sistem yang ada dalam rujukan kesehatan sehingga sistem rujukan tersebut tidak dapat tersosialisasi dengan baik. Memberikan pelayanan informasi dan komunikasi yang berkualitas dan efektif meningkatkan kepercayaan pasien yang pada akhirnya menciptakan komitmen yang kuat yaitu komitmen terhadap koneksi. Pentingnya komunikasi antar organisasi sejalan dengan penelitian yang dilakukan oleh Kurniawati et al. (2018) terhadap peserta BPJS di Bali. Hasil temuan mengindikasikan bahwa terdapat pengaruh signifikan komunikasi organisasi terhadap keluhan pasien melalui pengetahuan karyawan.

Komunikasi antara Puskesmas, Di- nas Kesehatan dan BPJS Kesehatan dalam sistem rujukan kesehatan juga sangat mempengaruhi implementasi pelaksanaan kebijakan. Untuk keberhasilan implementasi suatu kebijakan diperlukan beberapa syarat antara lain komunikasi dan koordinasi yang sempurna. Komunikasi merupakan perekat organisasi dan koordinasi merupakan sumber kerjasama tim dan membentuk sinergi untuk mempengaruhi pelayanan dan mutu pelayanan kesehatan bagi masyarakat pengguna jasa. Dari hasil penelitian dapat disimpulkan bahwa model komunikasi antara BPJS Kesehatan dengan Puskesmas adalah kolaboratif sedangkan model komunikasi antara BPJS Kesehatan dengan unit medis adalah instruktif.

\section{Sistem Transportasi}

Guna menunjang penyelenggaraan sistem rujukan kesehatan yang efektif, Puskesmas harus didukung dengan sarana transportasi untuk pengantaran pasien gawat darurat ke tempat rujukan. Berdasarkan hasil penelitian dan hasil observasi di 
lapangan, dapat dikemukakan bahwa di setiap Puskesmas sudah tersedia kendaraan operasional Puskesmas dalam hal ini mobil Ambulance yang siap setiap saat untuk dimanfaatkan oleh pasien rujukan Puskesmas ke tempat rujukan walaupun terkadang tidak dimanfaatkan oleh pasien yang sudah memiliki kendaraan pribadi.

Ambulans adalah sebuah unit transportasi yang disediakan oleh pihak Puskesmas. Seluruh Puskesmas dalam penelitian ini menyediakan layanan ambulans yang digunakan untuk membantu masyarakat dalam memberikan pertolongan pertama dan perawatan intensif saat pasien berada dalam perjalanan menuju Rumah Sakit rujukan. Di seluruh Puskesmas yang diteliti, pelayanan ambulans juga seringkali dimanfaatkan untuk sarana transportasi pasien rujukan kasus kegawatdaruratan maternal seperti penanganan ibu hamil dengan perdarahan, preeklamsia, maupun persalinan dengan kehamilan risiko tinggi yang tidak dapat ditangani di Puskesmas karena keterbatasan fasilitas dan tenaga ahli.

Ambulance merupakan salah satu sarana kesehatan yang memiliki peran penting dalam pelayanan kesehatan perseorangan (Kaporina et al., 2017). Pada sistem pelayanan gawat darurat Puskesmas, ambulance berperan dalam pelayanan gawat darurat pasien rujukan dari Puskesmas ke fasilitas kesehatan tingkat lanjut. Berdasarkan penelusuran peneliti, ambulance di Puskesmas seringkali dimanfaatkan hanya untuk mengantar pasien rujukan gawat darurat ke fasilitas kesehatan tingkat lanjut, pasien gawat darurat yang dimaksud biasanya terkait dengan pasien yang sebe- lumnya telah mendapatkan perawatan awal di Puskesmas, namun dikarenakan kurangnya sarana dan prasarana di Puskesmas maka dengan terpaksa harus dirujuk untuk mendapatkan perawatan lebih lanjut di fasilitas kesehatan lanjutan dengan fasilitas yang lebih lengkap guna penyelamatan nyawa pasien. Sedangkan pada pasien yang datang khusus hanya mengambil rujukan di Puskesmas sangat jarang memanfaatkan ambulance Puskesmas, hal ini dikarenakan pasien dengan kondisi tersebut tidak masuk dalam kategori gawat darurat sehingga tidak dibutuhkan pengantaran ke tempat rujukan dengan ambulance. Terkadang ada juga pasien gawat darurat yang sudah membawa kendaraan sendiri dari rumah sehingga tidak memerlukan pengantaran ke tempat rujukan dengan ambulance. Untuk kasus gawat darurat namun ambulans di Puskesmas tidak tersedia, terkhusus pada pasien yang tidak membawa kendaraan pribadi, maka dengan terpaksa akan menggunakan sarana transportasi umum guna pengantaran ke fasilitas rujukan tingkat lanjut, biaya transportasi nantinya akan dibebankan kepada pasien yang bersangkutan.

\section{Kepuasan Pasien}

Berdasarkan hasil penelitian dapat dikemukakan bahwa dalam hal pelayanan rujukan di Puskesmas sebagian besar pasien merasa cukup puas dengan pelayanan petugas kesehatan di Puskesmas. Dari hasil penelusuran peneliti kepuasan dirasakan pasien dikarenakan akses yang lebih dekat dari rumah ke tempat pelayanan kesehatan, keramahan para petugas kesehatan dalam melayani pasien, fasilitas penunjang yang 
dirasakan cukup memadai oleh pasien dan berbagai hal lain yang bersifat positif di mata masyarakat yang dalam hal ini adalah penerima manfaat layanan Puskesmas.

Terdapat beberapa indikator kepuasan yang dapat digunakan untuk mengetahui kualitas atau mutu pelayanan yaitu seperti indikator reliability, assurance, tangibles, empathy, dan responsiveness (RATER) (Jandavath \& Byram, 2016; Mohammadi-Sardo \& Salehi, 2019; Akbar \& Jaya. 2017; Barghouthi \& Imam, 2018; Wulandari et al., 2019).

Berdasarkan penelusuran pada informan, indikator-indikator pada faktor tangible telah terpenuhi dalam pelayanan di seluruh Puskesmas yang masuk dalam sampel. Indikator yang dimaksud antara lain sebaiknya penampilan petugas kesehatan dalam melayani pasien, kenyamanan tempat pelayanan, petugas yang disiplin dalam melaksanakan pelayanan pada pasien dan kemudahan proses dan akses layanan yang sudah menggunakan aplikasi alat bantu dalam melakukan pelayanan. Hal ini sejalan dengan penelitian. Hal ini sejalan dengan penelitian yang dilakukan oleh Fitriyanah et al. (2017) yang melakukan penelitian di RSUD dr. H Soewondo Kendal dan menemukan perbedaan yang signifikan antara tingkat kepuasan pasien BPJS dan pasien umum tentang mutu pelayanan keperawatan. Selain itu penelitian di RS Ludira Husada yang dilakukan oleh Lesmana \& Norwakiah (2021) menemukan hubungan antara keluhan dan kepuasan pasien peserta BPJS serta terdapat hubungan bermakna antara keluhan pelayanan dengan kepuasan pasien. Dalam penelitiannya sebanyak $18,6 \%$ pasien mengeluhkan pelayanan kesehatan yang diberikan, serta $42,3 \%$ merasa tidak puas.

Indikator yang masuk pada faktor reliability juga telah terpenuhi berdasarkan hasil penelitian yang dilakukan, yang dapat dilihat pada kecermatan petugas kesehatan dalam melayani pasien, adanya standar pelayanan yang jelas di setiap Puskesmas, kemampuan dan keahlian petugas menggunakan alat bantu dalam proses pelayanan, dalam hal ini petugas kesehatan dalam memeriksa pasien pasien dan petugas administrasi dalam melakukan pendataan pasien dan merujuk pasien.

Faktor ketiga juga sudah dirasakan terpenuhi oleh pasien, hal ini berdasarkan indikator-indikator yang antara lain petugas kesehatan yang cepat tanggap dalam merespon pelanggan yang ingin mendapatkan pelayanan dan dilakukan dengan cermat serta mampu merespon semua keluhan pasien. Pada Indikator faktor assurance, beberapa indikator yang terpenuhi antara lain adanya jaminan ketepatan waktu pelayanan dari petugas kesehatan yang memiliki legalitas dalam melakukan pemeriksaan dan kepastian biaya dalam pelayanan oleh BPJS Kesehatan.

Namun dalam faktor emphaty, sebagian besar indikator tidak terpenuhi dalam layanan rujukan di Puskesmas yang antara lain pasien kebanyakan memilih tempat rujukan lanjutan yang secara otomatis tidak dapat diakomodir oleh petugas kesehatan karena terbentur oleh aturan BPJS Kesehatan sehingga secara otomatis petugas tidak dapat mendahulukan kepentingan pasien, beberapa petugas juga tidak mela- 
yani pasien dengan ramah berdasarkan hasil FGD dengan pasien.

Dari hasil penelitian juga ditemukan bahwa ketidakpuasan hanya ada pada pasien yang tidak mau mengikuti aturan baru mengenai alur rujukan pasien yang telah ditetapkan BPJS dengan memilih tempat rujukan sendiri. Saat ini layanan dalam pengaturan perawatan kesehatan semakin terstruktur. JKN menerapkan sistem pelayanan medis. Dimana sistem tersebut meliputi FKTP dan FKTL meliputi pelayanan kesehatan sekunder dan tersier. Pasien yang ingin menerima pelayanan medis harus beradaptasi dengan sistem di berbagai tingkatan. Pasien tidak dapat menerima pelayanan dari FKTL secara langsung tetapi harus melalui proses bertingkat dengan sistem rujukan.

Menurut regulasi tidak semua penyakit bisa diperiksa secara langsung. Namun banyak pasien tidak mengetahui hal ini. Selain itu pasien yang membutuhkan rujukan harus hadir dan menjalani skrining terlebih dahulu di FKTP. Namun banyak pasien yang tidak datang hanya dirujuk oleh perwakilan keluarganya. Setelah menerima penolakan tersebut banyak keluarga pasien tidak puas dengan layanan rujukan medis Puskesmas.

Sistem rujukan dilaksanakan sebagai bentuk saling tugas dan tanggung jawab pelayanan medis baik vertikal maupun horizontal bagi pasien di semua fasilitas kesehatan. Oleh karena itu penting untuk terus mengevaluasi pelaksanaan sistem rujukan multi level di berbagai wilayah di Indonesia sehingga kualitas pelayanan kesehatan dapat terus ditingkatkan. Selain itu kurangnya pemahaman pasien terhadap sistem rujukan multiline juga menyebabkan masalah pelayanan yang tentunya berdampak pada persepsi masyarakat terhadap pelayanan medis dalam sistem JKN. Munculnya persepsi negatif sebagian masyarakat sangat mempengaruhi berjalannya sistem JKN. Harapan untuk memperbaiki sistem kesehatan dapat digagalkan oleh persepsi masyarakat yang buruk.

\section{Sosialisasi}

Hasil penelitian mengindikasikan dengan adanya kebijakan maupun aturan baru mengenai sistem rujukan kesehatan, BPJS secara wajib mensosialisasikan kepada penyelenggara layanan kesehatan berkoordinasi dengan Dinas Kesehatan selaku instansi yang membawahi seluruh Puskesmas di wilayahnya dan hal tersebut senantiasa dilaksanakan oleh BPJS Kesehatan. Hal tersebut telah terbukti berdasarkan pengakuan seluruh responden penanggung jawab Pcare di Puskesmas yang menyatakan bahwa setiap adanya perubahan regulasi, senantiasa disosialisasikan oleh BPJS Kesehatan baik melalui media sosial bila sifatnya berupa perubahan kebijakan pada aplikasi sistem rujukan kesehatan, maupun melalui sosialisasi secara langsung dengan melibatkan Dinas Kesehatan sebagai penanggung jawab Puskesmas dalam wilayahnya. Namun satu hal yang menjadi kendala adalah tidak tersosialisasi dengan baiknya regulasi yang ditetapkan oleh BPJS Kesehatan kepada masyarakat, hal ini terbukti dari hasil wawancara peneliti terkait dengan kepuasan pasien, masih banyaknya pasien yang tidak puas dengan pelayanan 
sistem rujukan berjenjang karena pada sistem tersebut masyarakat tidak dapat lagi memilih tempat rujukan sendiri. Apabila sosialisasi pada sistem rujukan berjenjang ini dilakukan dengan baik, seharusnya tidak ada lagi masyarakat yang memilih tempat rujukan sendiri, maka dengan begitu tidak akan menimbulkan rasa ketidakpuasan pasien pada pelayanan rujukan dari Puskesmas.

Berdasarkan hasil observasi peneliti dari berbagai macam sumber, sosialisasi antara BPJS Kesehatan dengan masyarakat sudah berjalan. Terbukti dengan banyaknya pengguna yang mencapai $70 \%$ dari total penduduk di Indonesia dalam penyelenggaraannya yang baru dimulai beberapa tahun yang lalu. Hal ini juga terjadi pada masyarakat di Kota Kendari dan Kota BauBau Provinsi Sulawesi Tenggara. Komunikasi antara BPJS Kesehatan dengan masyarakat di daerah tersebut sudah cukup baik, walaupun ada beberapa hal yang harus menjadi bahan perhatian.

Pengetahuan mengenai informasi sistem rujukan kesehatan menjadi sangat penting bagi mitra kerja BPJS Kesehatan, karena BPJS Kesehatan merupakan program yang menjadi tumpuan harapan, baik bagi masyarakat yang menjadi objek pelayanan kesehatan, maupun pemerintah sebagai penyelenggara pelayanan bidang kesehatan. Sistem rujukan BPJS Kesehatan tersebut harus dipahami oleh seluruh masyarakat, baik oleh calon peserta maupun peserta BPJS Kesehatan definitif. Pemahaman sistem rujukan BPJS Kesehatan tersebut untuk menjamin agar pemberian layanan kesehatan dengan fasilitas BPJS
Kesehatan dapat berlangsung sesuai prinsip kualitas pelayanan yaitu cepat, tepat, hemat, murah, mudah, dan ramah. Namun sistem rujukan BPJS Kesehatan tersebut belum banyak dipahami masyarakat, baik calon peserta BPJS Kesehatan maupun yang telah menjadi peserta BPJS Kesehatan. Kenyataan membuktikan bahwa ditengahtengah masyarakat masih banyak peserta yang mengalami kesulitan dalam memanfaatkan fasilitas BPJS Kesehatan. Hal tersebut ditandai dengan masih banyak peserta BPJS Kesehatan yang berobat secara langsung ke fasilitas kesehatan tingkat lebih tinggi, tanpa memiliki rujukan dari tingkat yang lebih rendah. Sementara ketentuan telah menetapkan sistem rujukan BPJS Kesehatan secara baku, sehingga peserta BPJS Kesehatan tidak dapat memperoleh pelayanan kesehatan.

Berdasarkan hal diatas, sosialisasi juga seharusnya dilakukan oleh petugas kesehatan di fasilitas kesehatan yang bekerjasama dengan BPJS Kesehatan terutama dalam hal kegiatan pelayanan kesehatan di berbagai fasilitas kesehatan. Ada prosedur dan alur kegiatan pelayanan kesehatan di fasilitas-fasilitas kesehatan. Prosedur tersebut antara lain proses pendaftaran di setiap faskes yang ingin dituju, administrasi pelayanan kesehatan,serta sistem rujukan berjenjang. Tiga prosedur tersebutlah yang seharusnya gencar disosialisasikan ke masyarakat. Hal ini harus dipahami oleh masyarakat agar kegiatan pelayanan kesehatan berjalan lancar. Karena pentingnya pengetahuan masyarakat tentang prosedur alur pelayanan kesehatan, akan berdampak pada berkurangnya semakin pa- 
hamnya pengetahuan masyarakat pada sistem rujukan kesehatan dari tingkat Puskesmas dan meningkatkan kepuasan masyarakat pada kualitas pelayanan rujukan.

Keberhasilan sosialisasi sistem rujukan kesehatan sangat ditentukan pengetahuan dan pemahaman subjek/pelaksana serta objek/sasaran sosialisasi tersebut, sehingga akan menjadi langkah awal terpenting dalam menjalankan sosialisasi. Hal ini sejalan dengan penelitian yang dilakukan oleh Suryana (2020) yang menemukan bahwa ada hubungan antara pengetahuan tentang rujukan dengan pelayanan rujukan berjenjang secara online pada pasien di UPT Puskesmas Semplak kota Bogor.

Sosialisasi bagi suatu sistem memiliki tujuan untuk memecahkan masalah sosial dan memenuhi kebutuhan sosial, sehingga sosialisasi suatu sistem diharapkan dapat merubah masyarakat menjadi berpengetahuan, mengerti dan mampu memahami mengenai suatu sistem. Perubahan tersebut harus tercermin dari kemampuan untuk memecahkan masalah sosial dan memenuhi kebutuhan sosial. Berbagai tindakan yang dilakukan masyarakat dan telah memperoleh pesan melalui proses sosialisasi suatu sistem harus memiliki kemampuan untuk menyelesaikan masalah yang menjadi beban pada masyarakat, serta mampu memenuhi kebutuhan sosial.

\section{KESIMPULAN}

Terdapat keterkaitan konsep antara sistem kesehatan dengan konsep pelaksanaan sistem rujukan. Komunikasi yang terbangun dengan baik antara BPJS, Dinas
Kesehatan, Puskesmas dan pasien; ketersediaan ambulance di setiap Puskesmas; kepuasan pada sebagian besar pasien; sosialisasi yang senantiasa dilakukan setiap kali adanya perubahan kebijakan; pengawasan dilakukan melalui aplikasi HFIS dan lokakarya triwulanan Puskesmas; kedisiplinan petugas kesehatan dalam pelaksanaan aturan rujukan non spesialistik sangat tergantung pada ketersediaan sarana dan prasarana; kebijakan yang dilakukan untuk mengurangi angka rujukan non spesialistik yaitu senantiasa melakukan pelatihan pada tenaga kesehatan dan upaya pemenuhan fasilitas kesehatan guna penanggulangan 144 penyakit yang wajib tuntas di Puskesmas. Beberapa pertanyaan juga menyasar kepada intensitas kegiatan informan, yang secara otomatis kurang mampu menjawab keadaan sesungguhnya dikarenakan dalam kondisi pandemic covid 19 proses pelayanan, komunikasi, pelaporan dan pelatihan terkait pelayanan BPJS sangat jauh berkurang intensitasnya, sehingga peneliti harus menggali ingatan jangka panjang informan jauh sebelum pandemic covid 19 terjadi disaat pelayanan masih berjalan dengan normal. Diharapkan penelitian ini kedepannya dapat memperluas wilayah penelitian yaitu di Rumah Sakit yang merupakan tempat rujukan.

Puskesmas perlu melakukan peningkatan pengetahuan tenaga kesehatan melalui pelatihan-pelatihan baik itu untuk dokter maupun Pcare, melakukan edukasi ke masyarakat tentang proses rujukan di Puskesmas serta melakukan advokasi kepada pembuat kebijakan terkait peningkatan fasilitas kesehatan. Selain itu perlu 
melakukan perbaikan manajemen pelayanan seperti pengawasan, sosialisasi, pelatihan, serta penguatan pelayanan dasar dengan sumberdaya yang memadai berupa sarana dan peralatan sehingga kasus kasus yang seharusnya bisa ditangani di pelayanan dasar tidak perlu dirujuk.

\section{DAFTAR PUSTAKA}

Akbar, F. H., \& Jaya, M. T. (2017). Relationship between service quality on public health center and patient satisfaction. Glob $J$ Health Sci, 9(7), 96-102. https:// doi.org/10.5539/gjhs.v9n7p96

Alawi, M., Junadi, P., \& Latifah, S. N. (2017). Analisis Faktor-Faktor yang Berhubungan dengan Tingginya Rujukan Kasus Non Spesialistik Pasien Jaminan Kesehatan Nasional pada Puskesmas di Kabupaten Sukabumi Tahun 2015. Jurnal Ekonomi Kesehatan Indonesia, 2(1). http:// dx.doi.org/10.7454/eki.v2i1.1954

Amini, A., Doshmangir, L., Adham, D., \& Janati, A. (2017). Challenges Of Establishing Speciality Referral System In Iran's Health Sector (A Qualitative Study). Acta Medica Mediterranea, (October). https://core.ac.uk/ download/pdf/211573287.pdf

Anhar, Ahmad Loai, I. C. (2016). Studi Komparatif Pemanfaatan Pelayanan Kesehatan Pada Masyarakat Pedesaan Di Wilayah Kerja Puskesmas Poleang Barat Dengan Masyarakat Perkotaan Di Wilayah Kerja Puskesmas Lepo-Lepo Tahun 2015. Jurnal Ilmiah Mahasiswa Kesehatan, 1(2), 1-13. http:// ojs.uho.ac.id/index.php/JIMKESMAS/ article/view/654

Barghouthi, E. A. D., \& Imam, A. (2018). Patient Satisfaction: Comparative Study between Joint Commission International Accredited and Non- accredited Palestinian Hospitals. https://dspace.alquds.edu/ handle/20.500.12213/5047

BPJS Kesehatan Cabang Bau-Bau. (2019). Laporan BPJS Kesehatan Kota Bau-Bau Tahun 2018.

BPJS Kesehatan Cabang Kendari. (2019). Laporan BPJS Kesehatan Kota Kendari Tahun 2018.

Chabibah, N., \& Chalidyanto, D. (2014). Analisis
Rasio Rujukan Puskesmas Berdasarkan Kemampuan Pelayanan Puskesmas. Jurnal Administrasi Kesehatan Indonesia, 2(3). http://journal.unair.ac.id/downloadfullpapers-jaki0a897b56aefull.pdf

Fitriyanah, E., \& Utomo, T. P. (2017). Perbedaan Tingkat Kepuasan Pasien BPJS dan Pasien Umum tentang Mutu Pelayanan Keperawatan Unit Rawat Inap Kelas 3 RSUD Dr. H Soewondo Kendal. Jurnal Ilmu Keperawatan dan Kebidanan, 9(2). http:// ejournal.stikestelogorejo.ac.id/index.php/ jikk/article/view/600

Jandavath, R. K. N., \& Byram, A. (2016). Healthcare service quality effect on patient satisfaction and behavioural intentions in corporate hospitals in India. International Journal of Pharmaceutical and Healthcare Marketing. 10(1), 48-74. https://doi.org/10.1108/IJPHM $-07-2014-0043$

Kaporina, A., Setyawan, M. H., \& Novitasari, A. (2017). Gambaran Tingkat Kepuasan Pasien Terhadap Pelayanan Di Instalasi Rawat Inap Ruang B2 Tht \& Kulit Kelamin Rsup Dr. Kariadi Semarang. Prosiding Seminar $\mathrm{Na}$ sional \& Internasional. https:// jurnal.unimus.ac.id/index.php/psn12012010/ article/view/886

Kurniawati, M., Siswanto, S., \& Ratri, D. R. (2021). Pengaruh Komunikasi Organisasi Terhadap Keluhan Pelanggan yang Dimediasi Pengetahuan Karyawan Tentang Pelayanan Pasien BPJS Ranap. CHMK HEALTH JOURNAL, 5(2), 279-289. http://cyberchmk.net/ojs/index.php/kesehatan/article/ view/983

Lail, N. H. (2019). Kualitas Pelayanan Bidan dan Keluhan Pasien Dengan Loyalitas Pasien Pasca Persalinan Peserta BPJS. Jurnal Ilmiah Kebidanan Indonesia, 9(01), 36-46. https://doi.org/10.33221/jiki.v9i01.213

Lesmana, T. C., \& Norwakiah, N. (2021). Keluhan dengan Kepuasan Pasien Rawat Jalan Jaminan Kesehatan Nasional di Rumah Sakit Ludira Husada Tama. Jurnal Endurance: Kajian Ilmiah Problema Kesehatan, 6(1), 70 -83. http://publikasi.lldikti10.id/index.php/ endurance/article/view/141

Meesala, A., \& Paul, J. (2018). Service quality, consumer satisfaction and loyalty in hospitals: Thinking for the future. Journal of Retailing and Consumer Services, 40, 261-269. 
https://doi.org/10.1016/

j.jretconser.2016.10.011

Mohammadi-Sardo, M. R., \& Salehi, S. (2019). Emergency department patient satisfaction assessment using modified servqual model; a cross-sectional study. Advanced journal of emergency medicine, 3(1). https:// dx.doi.org/10.22114\%2FAJEM.v0i0.107

Moorman, C., Zaltman, G., \& Deshpande, R. (1992). Relationships Between Providers And Users Of Market Research: The Dynamics Of Trust Within And Between Organizations. Journal Of Marketing Research, 29(3), 314. https://doi.org/10.2307/3172742

Naseriasl, M., Janati, A., Amini, A., \& Adham, D. (2018). Referral System In Rural Iran : Improvement Proposals. Cadernos De Saude Publica, 34(3). https:// Doi.Org/10.1590/0102-311x00198516

Novitasari, D. E., Arso, S. P., \& Fatmasari, E. Y. (2018). Analisis Pelaksanaan Penanganan Keluhan Pelanggan dan Pelayanan Informasi Di BPJS Kesehatan Kantor Cabang Semarang. Jurnal Kesehatan Masyarakat (Undip), 6(5), 39 - 51. https:// ejournal3.undip.ac.id/index.php/jkm/article/ view/21975

Prasetiawan, M. J., Mulyadi, E., \& Aliftitah, S. (2019). Pemahaman Tentang Hak Dan Kewajiban Peserta BPJS Kesehatan Di Puskesmas Ganding Sumenep. Journal Of Health Science (Jurnal Ilmu Kesehatan), 4 (2), 25-27. https://doi.org/10.24929/ jik.v4i2.708

Ratnasari, D. (2017). Analisis Pelaksanaan Sistem Rujukan Berjenjang Bagi Peserta JKN di Puskesmas X Kota Surabaya. Jurnal Administrasi Kesehatan Indonesia, 5(2), 145-154. . http://dx.doi.org/10.20473/

jaki.v5i2.2017.145-154
Sari, F. N., Zulfendri, \& Sanusi, S. R. (2020). Referral demand of patients in Pantai Cermin public health center Langkat. Britain International of Humanities and Social Sciences (BIoHS) Journal, 2(1), 314-320. https:// doi.org/10.33258/biohs.v2i1.194

Suryana, A. A. Y. (2020). Hubungan Pengetahuan Tentang Rujukan Dengan Pelayanan Rujukan Berjenjang Secara Online Pada Pasien Bpjs Kesehatan: Hubungan Pengetahuan Tentang Rujukan. Jurnal Ilmiah Wijaya, 12 (2). https://jurnalwijaya.com/index.php/ jurnal/article/view/108

World Health Organization (2008). Referral Systems - a summary of key processes to guide health services managers. https:// www.who.int/management/

Referralnotes.doc

Wulandari, R. D., Ridho, I. A., Supriyanto, S., Qomaruddin, M. B., Damayanti, N. A., Laksono, A. D., \& Rassa, A. N. F. (2019). Pengaruh Pelaksanaan Akreditasi Puskesmas Terhadap Kepuasan Pasien. Media Kesehatan Masyarakat Indonesia, 15(3), 228-236. https://journal.unhas.ac.id/ index.php/mkmi/article/view/6195

Yusuf, E., \& Awwaliyah, I. (2018). The Implementation of Indonesian National Health Insurance Programme: How Satisfiedwerethe Insured Participants and the Healthcare Providers?. Journal of Consumer Sciences, 3 (2), 27-42. https://doi.org/10.29244/ jcs.3.2.27-42

Zulhadi, Trisnantoro, L., \& Zaenab, S. N. (2013). Problem Dan Tantangan Puskesmas Dan Rumah Sakit Umum Daerah Dalam Mendukung Sistem Rujukan Maternal Di Kabupaten Karimun Provinsi Kepri Tahun 2012. Jurnal Kebijakan Kesehatan Indonesia: JKKI, 2(4).189-201. https:// journal.ugm.ac.id/jkki/article/view/3203 